\title{
Effect of Surface Preparation on the Strength of FRP-to-Mild Steel and FRP-to-Stainless Steel Joints
}

\author{
S.J. Kim, S.T. Smith (stsmith@hku.hk) \& B. Young \\ Department of Civil Engineering, The University of Hong Kong, Hong Kong, China
}

\begin{abstract}
A detailed understanding of the strength and behaviour of the bond between fibre-reinforced polymer (FRP) composites to metals is an ongoing field of research. The many different geometrical and material parameters make for extensive research demands. This paper in turn reports a series of tests on the shear strength and behaviour of FRP-to metal joints in which the main test parameters, which have received limited attention to date, consists of (i) type of metal (i.e. non-galvanised mild steel and stainless steel), and (ii) surface preparation technique (i.e. different mechanical abrasion methods). All specimens are loaded in displacement control which enables the failure process to be followed and identification of different failure modes to be made. The results enable the effectiveness of different surface preparation techniques upon the bond of FRP to different types of metals to be made.
\end{abstract}

\section{INTRODUCTION}

Externally bonded fibre-reinforced polymer (FRP) composites can strengthen metallic members (Hollaway and Teng 2008). For example, Silvestre et al. (2008) showed the load-carrying capacity of coldformed steel lipped channel columns strengthened by FRP to be enhanced by up to $20 \%$ above control specimens. The effectiveness of the strengthening is, however, largely dependent upon the quality of the bond between the two materials. In particular, understanding the effect of different surface preparation techniques, in addition to the effect of such techniques on different metals, are two important issues which have received limited attention to date.

In adhesively bonded FRP-to-FRP joints, failure has been classified into seven distinct modes (ASTM D5573-99 2005) namely; (i) adhesive failure $(\mathrm{ADH})$, (ii) cohesive failure $(\mathrm{COH})$, (iii) thinlayer cohesive failure (TLC), (iv) fibre-tear failure (FT), (v) light-fibre-tear failure (LFT), (vi) stockbreak failure (SB), and (vii) mixed failure (any combination of two or more failure modes). Further subdivision produces interfacial failure (i.e. $\mathrm{ADH}$, TLC, FT and LFT), cohesive failure (i.e. $\mathrm{COH}$ ), adherend failure (i.e. SB) and mixed failure. Such a classification system does not yet exist for FRP-tometal joints.

A commonly reported FRP-to-metal joint failure mode is interfacial failure (e.g. Xia and Teng 2005, Zhao and Zhang 2007). In such joints, the prepara- tion of the surface of the metal is an important parameter which requires further investigation.

A series of tests is reported in this paper on the shear strength and behaviour of single-lap FRP-tometal joints. The main test variables are (i) surface preparation, and (ii) type of metal. The results enable the most suitable surface preparation techniques to be determined for two different metals. In addition, the test results will also enable the future development and calibration of analytical models. A much more detailed account of the tests can be found in Kim et al. (2010).

\section{EXPERIMENTAL DETAILS}

\subsection{Test set-up and details of test specimens}

The single-lap shear test set-up utilised in this study is shown in Figure 1. In order to minimise bending of the test specimens, the metal plate was stiffened. The flexural rigidity ratio of the stiffened metal plates to FRP was over 13,000 which resulted in minimal bending of the metal plates during testing. The two main test parameters were (i) four different types of surface preparation techniques, and (ii) two different types of metals. The total number of test specimens was twenty-four (i.e. three identical test specimens for each of the eight test permutations). The properties of the two different metals (i.e. mild steel and stainless steel) are fully described in Section 2.2. The four different surface techniques of (i) 
solvent wiping, (ii) light sanding, (iii) grinding, and (iv) needling, are described in detail in Section 2.3.

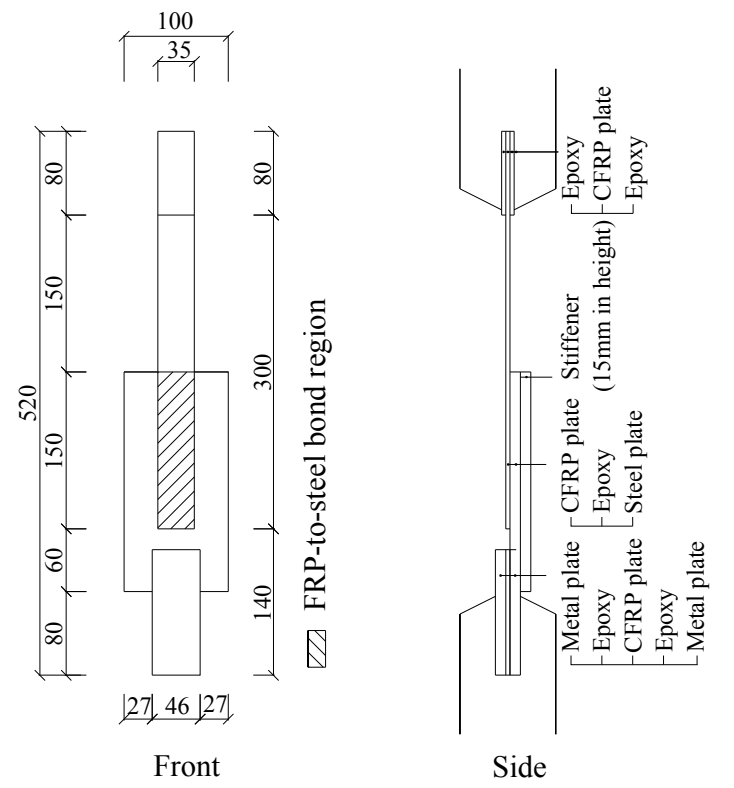

Figure 1. Test set-up.

A constant adhesive thickness was maintained by adhering small plastic prisms of equal size to the metal substrate prior to bonding of the FRP. Posttest measurements revealed an average adhesive thickness of $1.3 \mathrm{~mm}$ and standard deviation of 0.1 $\mathrm{mm}$. A long bond length of FRP (i.e. $150 \mathrm{~mm}$ ) and slow loading rate $(0.2 \mathrm{~mm} / \mathrm{min})$ was utilised in order to capture the full failure process of the joints.

\subsection{Materials}

All metal plates were nominally $9 \mathrm{~mm}$ thick. Three coupons were averaged to produce yield strengths of $322 \mathrm{MPa}$ and $426 \mathrm{MPa}$ and elastic moduli of $212 \mathrm{GPa}$ and $178 \mathrm{GPa}$ for the mild and stainless steels, respectively. Five FRP coupons (nominal thickness of $1.4 \mathrm{~mm}$ ) were tested and averaged to produce an elongation at rupture of $1.47 \%$, tensile strength of 3,367 MPa and elastic modulus of $230 \mathrm{GPa}$. Five dog-bone shaped epoxy adhesive samples were tested and averaged to produce an elongation at rupture of $0.36 \%$, tensile strength of $27 \mathrm{MPa}$ and elastic modulus of $8,886 \mathrm{MPa}$.

\subsection{Surface preparation}

The four different surface preparation techniques considered in this study were (i) no treatment (denoted as NT), (ii) sanding of the metal surface with fine sandpaper attached to an electric sander (i.e. 220 grit sandpaper comprising an average particle diameter of $68 \mu \mathrm{m}$ ) (denoted as SF), (iii) grinding of the metal surface with a $11000 \mathrm{rpm} 840 \mathrm{w}$ electric angle grinder fitted with a metal grinding wheel (denoted as GR) and (iv) needling of the metal surface with a pneumatically powered needle scaler containing $26 \times 2.8 \mathrm{~mm}$ diameter needles (denoted as NS). Prior to application of the FRP to all prepared surface, the surfaces were cleaned by wiping with a solvent (i.e. an aromatic and oxygenated solvent). The time which elapsed from the beginning of the surface preparation treatment to the application of the FRP was limited to 3 hours. Such limitation of time was primarily on account of minimising the oxidised layer that formed on the surface of the mild steel. Note that the stainless steel did not contain any form of protective coating.

For preparation by sanding (i.e. SF), the electric sander was applied for 3 minutes with new sandpaper used for each specimen. Of the three minutes, one minute was devoted to sanding parallel to the longitudinal axis of the plate and then one minute for $\pm 45^{\circ}$ to the longitudinal axis. The grinding and needling techniques were also applied for 3 minutes for each specimen although in no specific manner. In the case of grinding, an optimal surface preparation was achieved when the base metal was exposed. Optimal needling occurred when the complete bond surface was affected. In the case of sanding (i.e. SF), a very small portion of the mild steel oxide layer was removed (Figure 2b). In the case of grinding, the bare steel was exposed (Figure 2c) for the mild steel although the surface texture was the same for both mild steel and stainless steel. The needling left minor impressions on the surface for both mild steel and stainless steel and partially removed the oxide layer from the mild steel (Figure 2d).

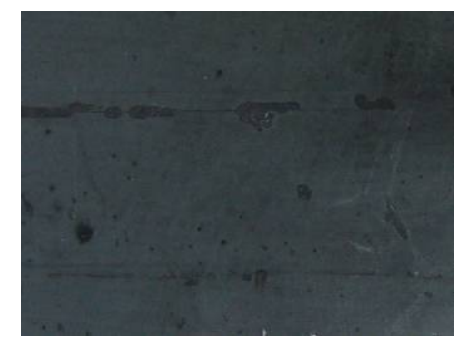

(a) No treatment (NT)

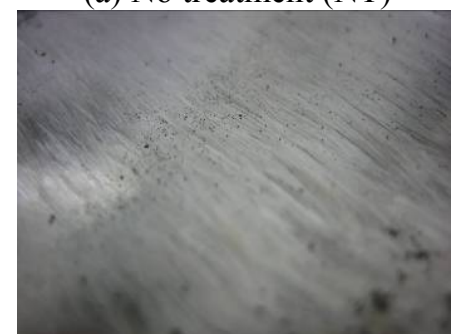

(c) Grinding (GR)

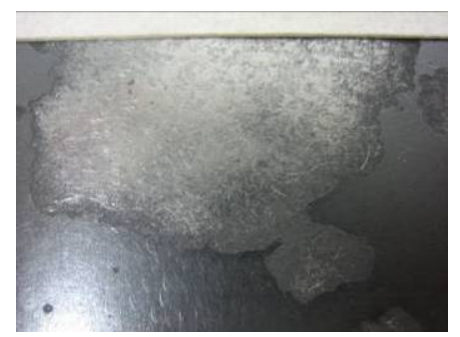

(b) Sanding (SF)

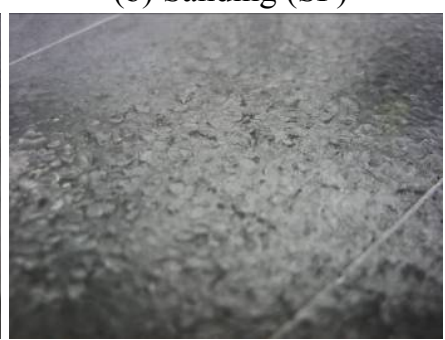

(d) Needling (NS)
Figure 2. Surface preparation techniques.

\section{TEST RESULTS}

A summary of the measured adhesive thickness and FRP plate dimensions in addition to the failure loads and failure modes are provided in Table 1. 


\subsection{Failure modes}

All specimens failed by debonding which generally occurred in a sudden manner. The failure sequence involved initial cracking between the FRP and metal at the loaded plate end (Figure 3a) which then propagated toward the plate end (Figure $3 b$ ). The modes of failure can be categorised into two main categories (i.e. Modes 1 and 2) as per the following. One of the failure modes is further sub-divided.

Mode 1: Adherend failure in oxidised layer

Mode 2A: Thin-layer cohesive failure in metal-toadhesive interface

Mode 2B: Thin-layer cohesive failure in FRP-toadhesive interface

Mode 2C: Mixed thin-layer cohesive failure
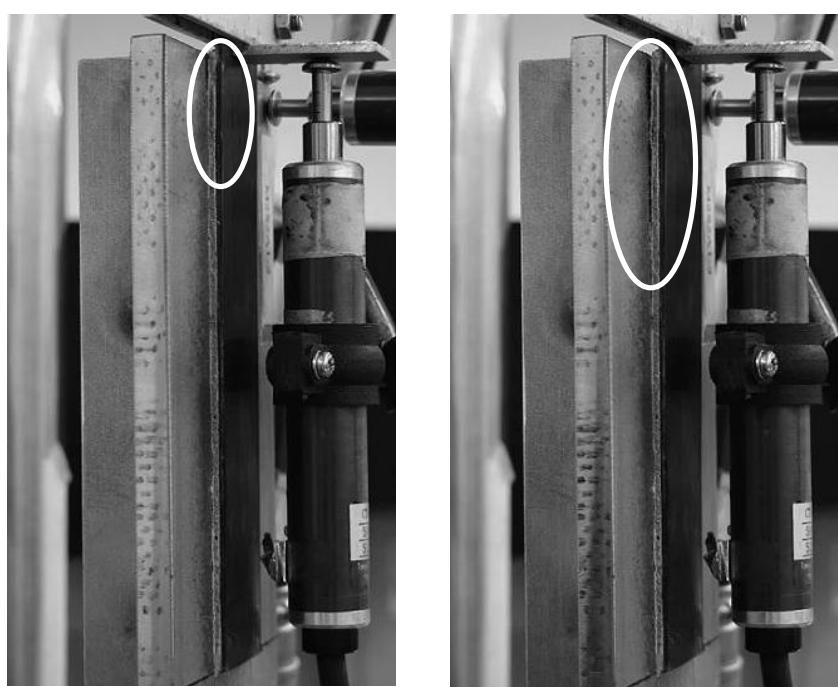

Figure 3. Debonding crack (SS-NS-2).

Table 1 Test results

\begin{tabular}{|c|c|c|c|c|c|}
\hline \multirow[t]{2}{*}{ Specimen* } & \multirow{2}{*}{$\begin{array}{c}\text { Adhesive } \\
\text { Thickness }^{\#} \\
(\mathrm{~mm})\end{array}$} & \multicolumn{2}{|c|}{ FRP } & \multirow{2}{*}{$\begin{array}{c}\mathrm{P}_{\mathrm{u}} \\
(\mathrm{kN})\end{array}$} & \multirow{2}{*}{$\begin{array}{c}\text { Failure } \\
\text { Mode }\end{array}$} \\
\hline & & $\begin{array}{l}\text { Width }^{\#} \\
\text { (mm) }\end{array}$ & $\begin{array}{c}\text { Length }^{\#} \\
\text { (mm) }\end{array}$ & & \\
\hline MS-NT-1 & 1.5 & 36.0 & 150.7 & 28.0 & Mode 1 \\
\hline MS-NT-2 & 1.4 & 36.0 & 150.3 & 22.9 & Mode 1 \\
\hline MS-NT-3 & 1.3 & 36.0 & 150.6 & 30.4 & Mode 1 \\
\hline MS-SF-1 & 1.3 & 35.7 & 150.3 & 32.5 & Mode 1 \\
\hline MS-SF-2 & & 35.4 & 152.3 & 31.5 & Mode 1 \\
\hline MS-SF-3 & 1.4 & 36.3 & 150.7 & 35.9 & Mode 1 \\
\hline MS-GR-1 & & 35.1 & .0 & 33.0 & Mode 2B \\
\hline MS-GR-2 & 1.5 & 35.7 & 151.0 & 34.5 & Mode 2B \\
\hline MS-GR-3 & 1.3 & 35.2 & 150.2 & 33.8 & Mode 2B \\
\hline MS-NS-1 & 1.2 & 35.4 & 151.2 & 31.7 & Mode 2B \\
\hline MS-NS-2 & 1 . & 36.1 & 151.4 & 31.7 & Mode 2B \\
\hline MS-NS-3 & 1.3 & 34.8 & 153.6 & 36.2 & Mode 2B \\
\hline SS-NT-1 & 1 & 35.1 & 151.4 & 35.5 & Mode 2A \\
\hline SS-NT-2 & 1.5 & 35.6 & 151.6 & 33.4 & Mode 2A \\
\hline SS-NT-3 & 1.3 & 36.2 & 152.1 & 37.5 & Mode 2A \\
\hline SS-SF-1 & 1.4 & 35.9 & 150.9 & 35.8 & Mode $2 \mathrm{~B}$ \\
\hline SS-SF-2 & 1.3 & 35.8 & 150.5 & 41.3 & Mode $2 \mathrm{~B}$ \\
\hline SS-SF-3 & 1.4 & 34.9 & 150.6 & 37.4 & Mode 2B \\
\hline SS-GR-1 & 1.5 & 34.7 & 149.8 & 34.8 & Mode 2C \\
\hline SS-GR-2 & 1.4 & 35.9 & 151.6 & 37.0 & Mode 2C \\
\hline SS-GR-3 & 1.4 & 35.4 & 151.3 & 35.0 & Mode 2C \\
\hline & 1. & 36.2 & 150.3 & 32.2 & $2 \mathrm{~A}$ \\
\hline SS-NS-2 & 1.3 & 36.1 & 150.7 & 31.0 & Mode $2 \mathrm{~A}$ \\
\hline
\end{tabular}

\begin{tabular}{l|l|l|l|l|l} 
SS-NS-3 & 1.3 & 35.0 & 151.3 & 33.0 & Mode 2A
\end{tabular} * MS (Mild steel)/SS (Stainless steel), NT (No treatment)/SF (Sanding)/GR(Grinding)/NS (Needling) \# Measured dimension

\section{Mode 1}

All six mild steel specimens with sanded surfaces or surfaces with no preparation failed in a Mode 1 manner (Figure 4). Figure 4a shows the failure interface to be located either purely in the oxidised layerto-base metal interface or in combination with the adhesive-to-oxidised layer (Figure $4 b$ ).

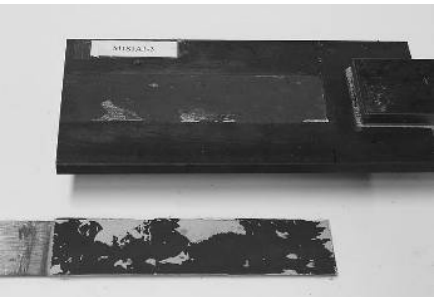

(a) MS-NT-3

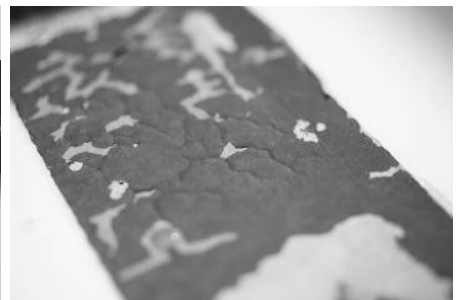

(b) Peeled off oxidised layer on metal surface
Figure 4. Mode 1 failure.

\section{Mode 2A}

Mode 2A failure occurred in all six stainless steel specimens prepared by needling or with no treatment. For these specimens, the epoxy was completely removed (Figure 5a) with a very thin layer adhesive (herein referred to as a light-dusting) remaining attached to the metal surface (Figure 5b).

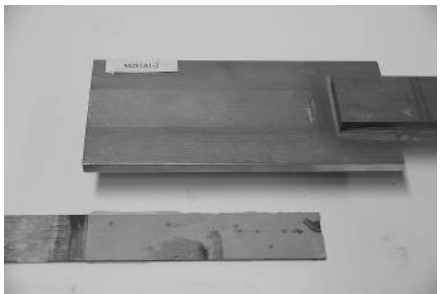

(a) SS-NT-1

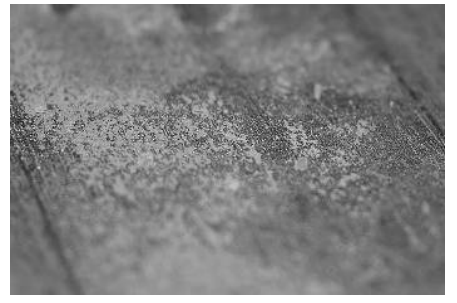

(b) Light-dusting of adhesive on stainless steel
Figure 5. Mode 2A failure.

\section{Mode 2B}

All mild steel specimens prepared with grinding or needling failed in a Mode 2B manner while the stainless steel specimens prepared with sanding also failed in the same manner. Similar to Mode 2A failures, all specimens exhibited near complete delamination ( $>90 \%$ of the bond region) of the FRP plate from the adhesive (Figure 6a) with a light-dusting of adhesive remaining attached to the FRP surface (Figure 6b). A very small portion of adhesive $(<10$ $\%)$ remained attached to the metal in the stainless steel specimens; in such cases the adhesive detached from the metal substrate (Figure 6b). In some cases, splitting of the FRP plates along the fibre direction was observed post-debonding failure.

Mode 2C 
This failure mode was observed in all three stainless steel specimens prepared by grinding. The failure interfaces were located in both the metal- and FRP-toadhesive layers (Figure 7). A light-dusting of adhesive was observed on the failure surfaces.

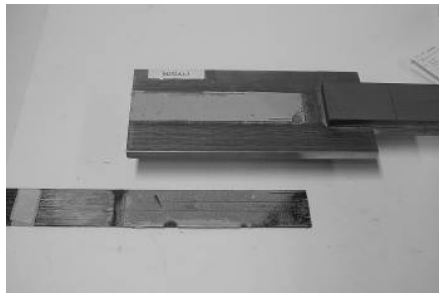

(a) SS-SF-2

Figure 6. Mode 2B failure

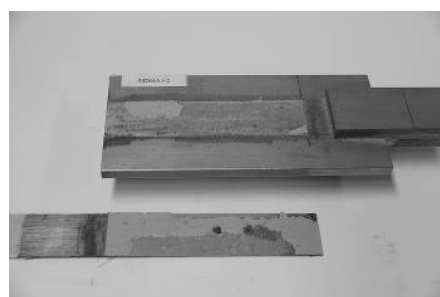

(a) SS-GR-2

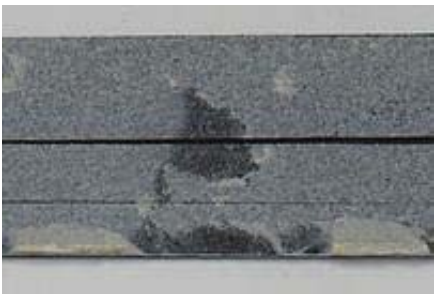

(b) Light-dusting of adhesive on FRP plate

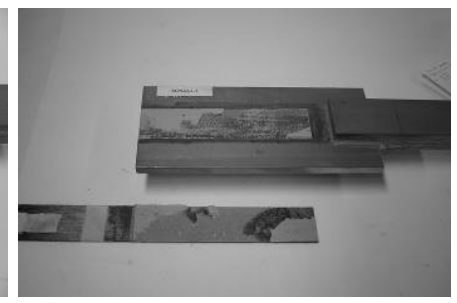

(b) SS-GR-3
Figure 7. Mode 2C failure.

\subsection{Effect of surface preparation techniques}

The effect of the different methods of surface preparation upon the stainless steel joints was much more obvious than the mild steel joints (Figure 8). The weak oxidised layer inherent in mild steel was the important contributing factor making the results less sensitive to the surface preparation method. Grinding was marginally the most optimal on average.

As the rate of oxidisation of stainless steel is well below that of mild steel, the former did not suffer from the same fate as the latter. As a result, Figure 8 reveals the optimal method of preparation for stainless steel is via sanding although there is a deal of scatter in the results. It would appear that the surface damage caused by the needle gun severely affects the strength of the bond for FRP-to-stainless steel. The strength of FRP-to-mild steel joints was superior to FRP-to-stainless steel joints.

\subsection{Load-displacement response}

Figure 9 shows typical load-displacement responses for both mild steel and stainless steel specimens. Typical responses for each of the four different surface preparation techniques for mild steel yielded slightly different behaviours, while all stainless steel specimens yielded approximately the same behaviour. Stainless steel exhibited a peak load plateau.

\section{CONCLUSIONS}

The fundamental behaviour and strength of FRP-tometallic joint assemblies, in which different metals have been prepared with different surface preparation techniques, have been reported. The most suitable preparation methods for mild-steel and stainless steel was grinding and sanding respectively. In addition, four distinct failure modes were observed. In the case of mild-steel, it is important to minimise the time allowed for oxidation to occur.

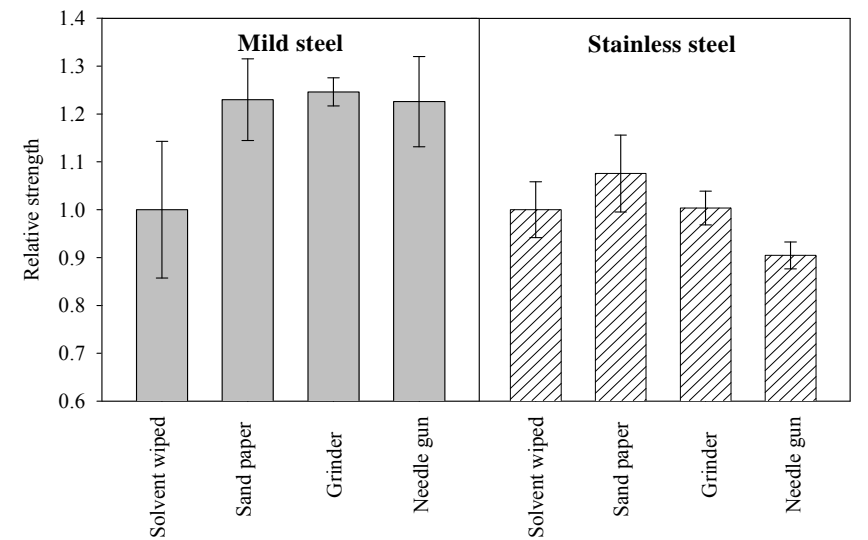

Figure 8. Relative strength enhancements (relative to solvent wiped specimens)

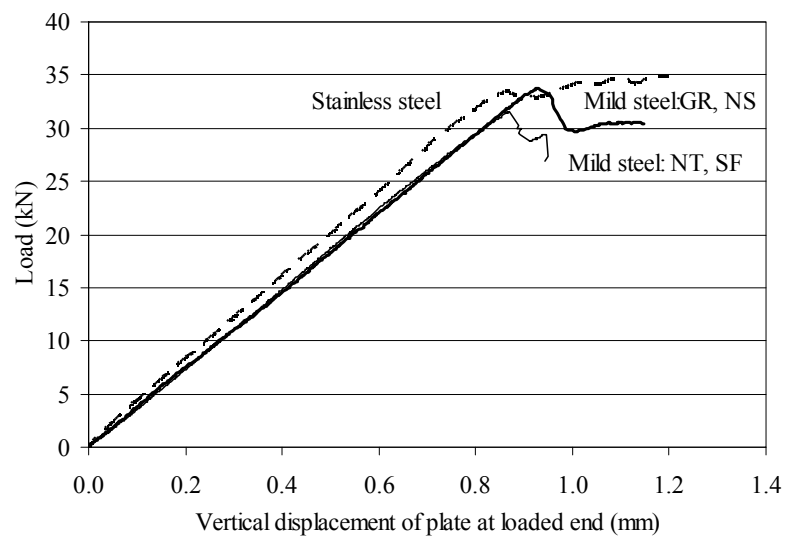

Figure 9. Load-displacement response.

\section{ACKNOWLEDGEMENT}

The authors are grateful to the assistance provided by Mr Joel LIU (2009-10 undergraduate final year project student of the University of Hong Kong).

\section{REFERENCES}

ASTM D5573-99 (2005) Standard Practice for Classifying Failure Modes in Fiber-Reinforced-Plastic (FRP) Joints, American Society for Testing and Materials (ASTM), USA.

Hollaway, LC \& Teng, JG 2008. Strengthening and rehabilitation of Civil Infrastructures using Fibre-reinforced Polymer (FRP) Composites, Woodhead Publishing, UK.

Kim, SJ, Smith ST, \& Young B 2010. "Effect of mechanical surface preparation on the strength and behaviour of FRPto-mild steel and FRP-to-stainless steel joints", in preparation. 
Silvestre, N, Young, B \& Camotim, D 2008. Non-linear behaviour and load-carrying capacity of CFRP-strengthened lipped channel steel columns, Eng. Struct., 30(10), 2613-2630.

Xia, SH \& Teng, JG 2005. Behaviour of FRP-to-steel bonded joints, Proceeding, Third International Symposium on Bond Behaviour of FRP in Structure (BBFS 2005), Hong Kong, 7-9 December, pp. 419-426.

Zhao, XL \& Zhang, L 2007. State-of-the-art review on FRP strengthened steel structures, Eng. Struct., 29(8), 1808-1823. 